\section{Em nome da "cultura": porta-vozes, mediação e referenciais de políticas públicas no Maranhão}

Eliana Tavares dos Reis ${ }^{1}$

Resumo: O artigo analisa um conjunto de práticas, recursos e representações ativadas por porta-vozes da "cultura" no Maranhão. Mediante a análise dos repertórios de mobilização, dos espaços de inserção e dos perfis sociais de agentes que disputam a autoridade legítima para definir o que é a "cultura" no estado, pretende-se revelar alguns dos condicionantes sociais que incidem no exercício da mediação cultural e no trabalho de produção de políticas públicas.

Palavras-chave: mediação; cultura; políticas públicas; cultura popular; patrimônio.

\section{Introdução}

$\mathrm{N}$ este artigo pretende-se fornecer indicações ${ }^{2}$ sobre práticas e concepções ativadas por porta-vozes da "cultura", bem como as bases do reconhecimento conquistado e do papel de mediador cultural exercido em um contexto histórico no qual a dimensão cultural ocupa um lugar de destaque na construção da identidade regional e das identidades específicas. Para tanto, foram examinados os repertórios de mobilização, os espaços de inserção e os perfis sociais de agentes alocados em posições relativamente bem situadas nos domínios de produção cultural e política no Maranhão. O que permitiu atentar, por um lado, para o trabalho de construção social conduzido por "especialistas" em concorrência (porta-vozes e mediadores) que identificam, registram e classificam aspectos que devem ser recuperados, conservados, enfim, louvados como padrão ou modelo exemplar. E, por outro lado, para a importância da tradução desses elementos na possibilidade de formular e administrar políticas para a "cultura". Assim, a reflexão recai também sobre dimensões relativas à produção de "políticas públicas" no Estado.

Tendo em vista o lugar relativamente estabelecido que as "políticas públicas" ocupam na agenda de pesquisas das ciências humanas e sociais, bem como nos embates políticos e ideológicos contemporâneos, é preciso fazer algumas ressalvas e explicitar alguns parâmetros que, espera-se, justificam as escolhas analíti-
Recebimento:

04.2010

Aprovado:

09.2010

1. Professora e pesquisadora do Departamento de Sociologia e Antropologia da Universidade Federal do Maranhão e do Programa de Pós-Graduação em Ciências Sociais da mesma instituição. Vinculada às linhas de pesquisas "Elites Políticas" e "Relações de Poder: políticas públicas, instituições e participação política", desenvolve pesquisas sobre elites culturais, engajamento e intervenção política. eliana1reis@terra. com.br

2. As considerações ora explicitadas têm como base os resultados preliminares de uma pesquisa mais ampla e em andamento sobre os porta-vozes e os referenciais de políticas públicas para a cultura no Maranhão. 
cas que orientam o tratamento dessa temática como elemento constituinte do objeto de estudo ora em questão. Isso porque a reflexão não se enquadra nas perspectivas mais usuais e normativas de análise das "políticas públicas" que, geralmente, desdobram-se em uma ou mais das seguintes direções: observar os mecanismos de implementação de modelos de gestão com base em um ideal de sociedade; avaliar as estratégias mais ou menos eficazes privilegiadas para a operacionalização de políticas; apontar (reivindicar/denunciar) as áreas, esferas, setores, etc. priorizados ou não pelos investimentos públicos; discutir as fronteiras disciplinares, teóricas e conceituais que devem cercar o "objeto".

Evidentemente, não se pode desconsiderar os processos históricos (como o de afirmação do valor e da prática democráticos nos Estados Modernos, bem como de "atores políticos" que conquistam reconhecimento como representantes de direitos legítimos, pautados pela garantia e/ou gestão de demandas sociais legítimas) que interferiram na possibilidade de institucionalização desta subárea, que toma "como objeto específico o estudo de programas governamentais, particularmente suas condições de emergência, seus mecanismos de operação e seus prováveis impactos sobre a ordem social e econômica" (Arretche, 2003: 8). No entanto, o trabalho que segue não se inscreve diretamente no universo de discussões orientadas pela descrição de mecanismos formais acionados nos processos decisionais, ou de avaliação das temáticas e procedimentos adotados, ou de elaboração de diagnósticos apontando falhas e potencialidades de engenharia política, ou de tentativa de prescrição de alternativas mais eficientes.

Nos termos colocados por Thoenig (1985),

Uma política pública é um problema quando ela se situa em um contexto social específico, por relação a objetos de disputas, a populações, a estruturas. Ela constitui uma realidade objetiva, pois ela afeta indivíduos, grupos, organizações ou classes nas suas atitudes, nos seus interesses e nas suas situações. A ação governamental produz e engendra efeitos práticos. Aquelas podem se traduzir por seu impacto sobre valores materiais, mas também sobre os símbolos ou sobre as representações. (Thoenig, 1985: 12)

Contudo, somente é possível entender os encaminhamentos administrativos na produção de bens e serviços específicos, assim como os seus impactos efetivos, inclusive em termos de representações - a conexão entre produtos operacionais e os efeitos de mudança societal (id., 2007: 20) -, quando se entende o porquê de determinados aspectos serem celebrados na elaboração de uma agenda pública. E, para tanto, é preciso sair do domínio da gestão e buscar os condicionantes sociais que incidem sobre a escolha dos gestores e da sua ação 
política e administrativa. Dessa forma, a política pública deixa de ser tomada apenas como processo e causa e passa a ser considerada como efeito de processos históricos e sociais mais amplos que definem o espaço das questões e dos procedimentos possíveis e legítimos. Sawicki (1999) demonstrou a oposição entre matrizes de estudos do "pessoal político" na França e nos EUA, enfatizando os prejuízos de uma "divisão do trabalho científico que tem engendrado - por razões diferentes - a separação das pesquisas sobre a seleção dos homens políticos e aquelas sobre a formulação de políticas públicas" (p. 163) ${ }^{3}$. Assim, defendendo o valor heurístico da convergência dessas abordagens, declara que "tudo se passa como se a partilha de tarefas tivesse finalmente ocultado a questão dos efeitos das propriedades sociais dos governantes - profissionais da política e funcionários - sobre os mecanismos de elaboração das decisões públicas" (ibidem).

Segue-se na direção de conjugar a investigação das características sociais dos agentes que ocuparam ou ocupam cargos políticos vinculados à gestão da "cultura" no Maranhão (confrontando-as com aquelas propriedades detidas por outros porta-vozes dessa dimensão) com o estudo das representações sociais compartilhadas e por eles mesmos edificadas nas suas dinâmicas de afirmação e de lutas pelos sentidos de "cultura". Com efeito, observa-se que o procedimento analítico mais apropriado contempla, no mínimo, três momentos significativos e indissociados do exame da produção e execução de políticas: 1) atenta-se para as condições históricas e sociais que favorecem a objetivação de determinadas problemáticas sociais e da autoridade dos seus porta-vozes (agentes que, por serem os responsáveis pela fabricação da problemática, constituem-se igualmente como "aptos" a agir sobre elas); 2) procura-se os fatores institucionais que interferem nas tomadas de decisão políticas propriamente ditas, levando em conta as estratégias de negociação, seleção e implementação de políticas compatíveis com os interesses proclamados e perseguidos por uma dada administração; e, finalmente, 3 ) examina-se os efeitos sociais que tais políticas provocam, graças, especialmente e novamente, às interpretações oferecidas por agentes interessados (mesmo que apenas "simbolicamente") em defini-las e avaliá-las conforme as suas disposições, posições e posicionamentos. Como expressou Thoenig (2007: 22), “a organização pública não detém a priori o monopólio de sua definição", ela depende de como:

Agrupamentos mais ou menos voláteis expressam opiniões não convergentes a respeito, selecionam aqueles que para eles fazem sentido, julgam, avaliam mais ou menos espontaneamente que impactos societais específicos constituem um sucesso ou um fracasso e se podem ser atribuídos a uma política específica endossada por uma instituição pública específica. (ibidem)
3. Tal como evidenciado para as análises dos "partidos políticos", há comumente, conforme Sawicki (1997), uma fragmentação das dimensões de análise que acaba dificultando a apreensão da multiplicidade de processos sociopolíticos que estão em jogo. Nas suas palavras: "o estudo de seu recrutamento deveria se vincular à sociologia da socialização e da legitimação, aquela do seu funcionamento interno à sociologia das organizações e da mobilização, aquela de sua gênese à sociologia da mudança social, da institucionalização e da politização, etc." (ibidem: 6, tradução nossa). Assim, as ênfases recairiam ou na busca e inventário do "nascimento", ou no "tipo de organização interna”, ou sua "ideologia", ou nas características socioprofissionais dos seus protagonistas. Por um lado, se teria a tradição francesa com o predomínio de estudos do tipo sociográficos, procurando as correlações entre determinadas instituições, organizações e os grupos sociais. Porém raramente levando em contar a "complexidade de mecanismos de representação" e o impacto de determinado tipo de recrutamento social sobre 
elas (Sawicki, 1997: 8). Por outro lado, a tradição anglo-saxônica, que seria mais centrada na análise de "circuitos de decisão e influência", desenvolvidas com base em "problemáticas elitistas ou poliárquicas" (ibidem).

4. Outro estudo, tendo como ênfase os "porta-vozes" (Reis, 2008a), sustenta o valor heurístico da análise das propriedades sociais, dos meios de afirmação e das disputas travadas entre lideranças autorizadas a falar em nome de "causas legítimas", naquele caso, evidenciando as condições de concorrência e efetivação de "modelos de sociedade" e políticas de "participação popular" no Rio Grande do Sul.
Deve-se sublinhar a importância proporcional e a associação entre os referidos momentos que não necessariamente obedecem a uma ordem cronológica. Pelo contrário, uma das principais dificuldades é justamente de estabelecer "o quê gera o quê" (o que não significa dizer que não é possível apontar o princípio gerador de práticas). Para o estudo em pauta, visa-se sugerir pistas da dinâmica de construção de objetos que devem ser ou são alvo de políticas. Ou seja, procura-se apreender o trabalho social mobilizado, sobretudo, por agentes especializados que, acionando suas "competências", identificam, definem, disputam definições, contribuem para o reconhecimento e legitimidade (realidade) de problemas sociais passíveis de serem consagrados como problemas políticos. Trata-se de levar em conta o trabalho de evocação, de enunciação e prescrição de determinadas "problemáticas" operado pelos agentes autorizados a fazê-lo, bem como dos mecanismos que garantem a imposição das mesmas no âmbito dos "debates públicos", levando à sua "consagração estatal" (Lenoir, 1998). E, da mesma maneira, está entre os objetivos de uma investigação mais atenta acerca da gênese social e política das agendas das políticas públicas analisar, como propõem Collovald e Gaïti (1991: 13), referindo-se ao estudo de Damamme (1987) e Thoenig (1985), "como se opera a cristalização das idéias do air du temps contribuindo para a imbricação das políticas locais das autoridades locais e das políticas locais do Estado".

Para o estudo dos porta-vozes da cultura no Maranhão, são, então, apreendidas, numa perspectiva relacional, as práticas e as concepções ativadas, bem como as bases do reconhecimento conquistado. Para tanto, por um lado, são examinados os repertórios de mobilização, os espaços de inserção e os perfis sociais dos agentes e, por outro lado, seus investimentos e estratégias no sentido de ocupar posições de destaque nos domínios de produção cultural e política. Focalizando os "porta-vozes", focaliza-se "uma voz autorizada" que "fala em nome" (e luta pela conservação ou subversão) de outras posições e posicionamentos ${ }^{4}$, aquele que detém o "cetro" para dizer o que é a "cultura". É preciso, pois, tratá-los como pertencentes a um "(...) sistema de relações objetivas no qual as posições e as tomadas de posição se definem relacionalmente e que domina ainda as lutas que visam transformá-lo" (Bourdieu, 1998: 175).

Tendo em vista a proposta de estudo em questão, as noções de referencial e de mediação de Jobert (1995) e Muller (1995) revelam-se particularmente procedentes. A primeira informa, justamente, o espaço de sentidos que permitem captar o mundo, as visões e di-visões do mundo social construídas na prática de grupos sociais portadores de determinadas características, que atuam e posicionam-se num dado campo de relações de força (ou de relações de poder que são, por sua vez, mediadas por sentidos compartilhados). No que tange ao trabalho de mediação, esse diz respeito ao processo de produção de conheci- 
mento e de produção de normas. Desse modo, aos mediadores cabe o trabalho de decodificação do mundo (descrição de como ele é) e de recodificação do mundo (prescrição de como deve ser), apontando as ações necessárias para a sua "melhoria" ou "transformação".

As duas noções são inseparáveis, pois o referencial é obra de indivíduos ou grupos, responsáveis (não necessariamente de forma consciente ou cínica) pela imposição da "verdade" do momento ou por sua modificação. É a matriz de referência que fundamenta as variadas modalidades de intervenções políticas de diversos atores, decorrente de mecanismos complexos de invenção ou reinvenção das problemáticas legítimas e dos seus porta-vozes. A mola propulsora de políticas públicas reside nas ações e reações, atrações e repulsas, escolhas e exclusões daqueles e entre aqueles (os mediadores) inseridos em contextos e domínios distintos.

Há um processo de objetivação e institucionalização decorrente desses movimentos em que os mediadores logram o lugar de "heróis/arautos do inelutável", nos termos de Muller (1995: 161), em um determinado contexto, sob determinadas condições e interesses sociais e particulares em jogo. Quer dizer, o “inelutável” está sempre em disputa e, portanto, é passível de ser modificado, substituído, redefinido, seja numa dinâmica quase imperceptível, seja de forma brusca numa situação de crise e mudança da matriz de referência, seja num nível localizado, seja numa transformação mais global.

A atuação dos mediadores também se objetiva com vistas à circunscrição das fronteiras de um lugar "singular" de inscrição, contribuindo para a afirmação do que lhe é ou deve ser "específico", de como pronunciá-lo, de como integrá-lo. A análise da delimitação dessas fronteiras explicita a posição de um domínio social em relação aos demais, sendo possível cercar as posições que os agentes desfrutam conforme os recursos detidos, as aproximações e as distâncias de uns em relação aos outros, bem como as questões relevantes das quais devem se ocupar. Entretanto, foi imprescindível verificar, por um lado, as cadeias de interdependências constituídas entre os lugares e os agentes que se posicionam, descrevem e prescrevem a "realidade" das "expressões" e políticas culturais no Maranhão e, por outro lado, a multidimensionalidade de princípios acionada nas estratégias de afirmação e nos repertórios de mobilização ${ }^{5}$.

Nesse caso, cabe enfatizar que a multiplicidade de recursos, lógicas e estratégias se traduzem nas igualmente múltiplas posições desfrutadas pelos agentes. Esta é produto e produtora de ligações que eles estabelecem no decorrer dos seus itinerários, uma das principais cauções do reconhecimento das "habilidades" e "competências" detidas ${ }^{6}$. Portanto, pode-se acentuar a importância das cadeias e elos criados entre os agentes, que assumem diferentes feições, tipos e níveis:
5. Tal perspectiva de análise das práticas de mediação se aproxima de estudos relativos à mediação política e à mediação cultural. Considerando tanto a especialização no papel de intermediação entre localidades e centros da vida política nacional e de trânsito entre domínios (Coradini, 1998a, Grill, 2008), quanto de investigações das lógicas levadas a cabo por agentes detentores de determinados tipos de capitais e reconhecimentos sociais que garantem sua multiposicionalidade e respaldam seu papel de mediador/ intérprete cultural (Seidl, 2007, Coradini, 1998b).

6. Sublinha-se que não se trata de relacionar o papel de "mediador" ou "porta-voz" à mera posse de recursos de "competência técnica". Para uma problematização dos usos e importações da noção de expertise e da atual consagração dos chamados "novos militantismos" em detrimento do que seriam os "velhos", "clássicos" ou "tradicionais" formas de militantismos políticos, ver Reis \& Grill (2008) e Reis (2008a). 
7. Ver Coradini (1995), Anjos (2002), Pécaut (1990), Reis (2008b), Reis \& Grill (2008), Seidl (2007).

8. O Perfil Cultural e Artístico do Maranhão, de 2006, foi publicado em CDROM e está acessível no sítio http:// www.perfilcultural. com.br/. Fomentado pela Companhia Vale do Rio Doce e a Associação de Apoio à Música e à Arte no Maranhão (AMAR$T E)$, as pesquisas aí reunidas foram realizadas por "consultores convidados e profissionais de reconhecida capacidade e experiência, especializados em diversas áreas objeto de pesquisa". Dentre esses "consultores", agentes que já ocuparam ou ocupam cargos na administração pública ou participam de instâncias vinculados ao debate e promoção de políticas na área de "cultura", além disso, dedicam-se a escrever sobre questões concernentes como "produtores de cultura" ou de um ponto de vista "acadêmico".
1) como articulação em torno de lugares (lieux) - instituições, organizações, setores, domínios, etc. - nos quais os agentes se inscrevem e configuram um ambiente (milieu) de afinidades variadas (Prochasson, 1993); 2) como o próprio nexo de interdependência entre setores sociais, estabelecido a partir dos múltiplos pertencimentos dos agentes que lhes exigem constantemente a ponderação sobre suas tomadas de posição (Sawicki, 1997); 3) como capital de relações sociais acumulado a partir das ligações mais ou menos institucionalizadas entre agentes "dotados de propriedades comuns (passíveis de serem percebidas pelo observador, pelos outros ou por eles mesmos), mas também unidos por ligações permanentes e úteis" (Bourdieu, 1998: 67); 4) e, finalmente, como relações diádicas, que são os vínculos horizontais ou verticais estabelecidos voluntariamente ou por obrigação entre duas pessoas de status próximo ou diferente, fundados em princípios de reciprocidade e que atuam nas trocas e nos deslocamentos operados pelos agentes (Landé, 1977). Tendo em vista a fraca objetivação das esferas sociais, a possibilidade de maximização das conexões criadas e o trânsito social decorrente de tais laços são potencializados pelo ineficaz jogo das jurisdições internas aos domínios sociais.

Para a operacionalização das dimensões de análise, foram exploradas as seguintes fontes de informações: o documento Perfil Cultural e Artístico do Maranhão 8 ; o livro Memórias de Velhos. Depoimentos. Memória oral da cultura popular maranhense; duas dissertações de mestrado sobre os temas "patrimônio" e "políticas públicas"; entrevistas em profundidade realizada com agentes com perfis representativos do universo de análise; e um conjunto de fontes de dados variadas, tais como, livros de memórias, repertórios biográficos, currículos lattes, entre outras.

A reflexão, nesse momento, dar-se-á em torno de duas "temáticas": o "patrimônio" (material) e a "cultura popular". Tal escolha se justifica, em primeiro lugar, pela representatividade dos perfis sociais, dos posicionamentos e da projeção social dos seus porta-vozes. Em segundo lugar, por encerrarem "expressões culturais" dominantes nos discursos e embates políticos, sociais e universitários no Maranhão; e, finalmente, por se constituírem em referências centrais na construção de múltiplas identificações. Soma-se a isso o fato de serem duas categorias abrangentes, que contam com significativos empreendimentos em termos de políticas públicas e, ainda que de formas variadas, acabam polarizando duas "tradições" e "influências" ("europeia" e "popular") reivindicadas nos discursos e que constituiriam a singularidade dos bens culturais do ou produzidos no Maranhão.

Antes de proceder à exposição e análise dos dados, cabe situar um dos principais elementos de homogeneização de um universo de agentes que se notabilizaram tanto pela produção de bens culturais dos mais variados tipos (música, teatro, poesia, literatura, etc.), como pela ocupação de cargos de comando em órgãos de cultura governamentais. Refere-se à regularidade dos mecanismos ativados 
para as reconstituições históricas oferecidas pelos mediadores culturais que se dispõem a definir alguma "expressão" da "cultura maranhense" ou a "explicar o Maranhão", entre outras. Estas comumente preveem, no mínimo, três fases de desdobramento da dinâmica regional, determinadas, mormente, pelo desempenho econômico do estado, a saber: o "auge", a "decadência" e as tentativas de "recuperação" de um lugar de proeminência nacional outrora possuído9.

A lógica cronológica parece combinar três modalidades de recontar o passado ou a trajetória do estado, dos seus eventos, feitos e personagens, quais sejam: 1) a busca de reconhecimento externo dos símbolos regionais (edificados para tanto) mediante a explicitação e certificação de elementos distintivos apropriados ao e no mercado mais geral de bens regionais legítimos; 2) no mesmo golpe, forjam-se as bases para a constante reinvenção e reconhecimento interno de um conjunto coerente e valorizante de aspectos que constituem a singularidade regional para os "nativos", interpelando pertencimentos e movendo o trabalho coletivo de construção de uma "memória" e de uma "identidade"; 3) finalmente, a pouca ousadia subversiva frente às reconstituições históricas consagradas talvez seja decorrente da necessidade de uma inscrição segura dos porta-vozes, autorizados a descrever e prescrever a história em uma genealogia de intérpretes. Sobre esse último ponto, vale mencionar as dificuldades em romper com uma doxa e os riscos de perda do reconhecimento social e dos pertencimentos identitários que correm os agentes heréticos ${ }^{10}$.

Pode-se ressaltar a recorrente evocação do chamado "período colonial", com a singular importância dada à Companhia Geral de Comércio do Grão-Pará Maranhão como a gênese cultural e, sobretudo, para estabelecer a preponderância da influência europeia no estado. Conforme Jomar Moraes ${ }^{11}$ (2006), é devido a esse período de prosperidade econômica que as "famílias enriquecidas na lavoura [passaram a] constituírem uma requintada aristocracia rural", residindo em casarões "com luxo e bom gosto" e viajando para "os grandes centros culturais europeus". A capital São Luís afirmava-se como "centro cultural" (Moraes, 2006). Realçando, em particular, o papel dos padres jesuítas para esse "início letrado das manifestações culturais", esse seria o cenário de emergência, por exemplo, do "primeiro ciclo literário propriamente maranhense", a partir do qual "além das vocações para a poesia e para a prosa literária, surgem historiadores, biógrafos, ensaístas e pesquisadores do passado" (ibidem). E, também, o berço do "gosto pela arte musical" e dos empreendimentos inaugurais nas primeiras encenações teatrais.

Segundo Josias Sobrinho ${ }^{12}$ (2006):

A história iniciada sob influência dos catequistas portugueses com seus benditos, ladainhas e teatro musicado, que teve seus primeiros mestres de banda vindos diretamente da corte, trazendo consigo a música produzida
9. Tais aspectos corroboram as análises de Alfredo Wagner Berno de Almeida (2008) acerca da cristalização de uma ideologia da decadência na produção e representação dos intelectuais no Maranhão.

10. Pode-se pensar nas "condições de felicidade" que a preservação de determinados consensos implica. Satisfação (pela simples aceitação) que, objetiva e subjetivamente, é garantida pelo desconhecimento das condições que the dá existência, "a qual, na medida em que define a relação dóxica com os rituais sociais, constitui a condição mais imperativa de sua realização eficaz" (Bourdieu, 1996: 95).

11. Jomar Moraes é advogado e membro da Academia Maranhense de Letras, da qual foi responsável pela pesquisa e textos da publicação "perfis acadêmicos". Neste, se autodefine como "Pesquisador, ensaísta, cronista, crítico e historiador da literatura maranhense". Ocupou uma série de cargos administrativos como o de diretor do Serviço de Administração da Secretaria de Educação e Cultura (1970-71); diretor da Biblioteca Pública do 
Estado (1971-73); diretor do Departamento de Assuntos Culturais da Fundação Cultural do Maranhão (1973-75); diretor do serviço de Imprensa e Obras Gráficas do Estado - Sioge (1975-80); diretor do Departamento de Assuntos Culturais da Universidade Federal do Maranhão (198185); secretário da Cultura do Estado do Maranhão (198587).

12. Josias Sobrinho é músico. Atuou no Laboratório de Expressões Artísticas (Laborarte), então coordenado por Tácito Borralho. Participou de um curso básico de iniciação que teria oportunizado o estudo da história da música e de teoria musical, acumulando um "conteúdo cientifico cultural" que the permitiu passar de monitor para instrutor de oficina no Laboratório. Foi coautor, com Borralho, em peças para bonecos e atores e compôs trilhas sonoras de alguns espetáculos montados por grupos de teatro do Maranhão. Iniciou o curso de Letras, mas não concluiu. Foi dono de uma livraria localizada no centro da cidade, junto com duas irmãs. É funcionário do Estado desde a década de 1980. Trabalhou na Fundação de Cultura do Município. Por quatro anos por lá, foi aqui se desenvolvendo aos poucos, constituindo uma identidade cultural própria, ao mesclar gentes e costumes. O circuito de óperas européias, a que o público da província maranhense pôde ter acesso durante os anos de ouro da economia do algodão, só favoreceu o desejo de freqüentar as praças de Lisboa e Paris. (Sobrinho, 2006)

E, em 1771, como afirma Tácito Borralho ${ }^{13}$ (2006), foi publicado "um alvará que recomendava que se instalassem na Colônia teatros públicos"; o início, em 1776, da construção do primeiro teatro de São Luís, efetivada somente em 1815, sendo que o primeiro espetáculo teria sido encenado somente em 1816 "em comemoração à Independência de Portugal".

Como será evidenciado, subsequentemente, nas justificações para a valorização da "arquitetura colonial", os agentes comungam com a ideia de que a decadência econômica se refletiu diretamente na produção cultural. Recolocando o declínio de um período áureo, reafirmam a necessidade de sua recuperação e, por esse intermédio, delineiam as condições favoráveis para sobrevalorizar iniciativas representativas das suas próprias inserções políticas e culturais no período recente. Quando passam a descrever a fase posterior à decadência, o principal elemento que parece demarcá-la e singularizá-la é a afirmação de um discurso de valorização da "cultura popular" que, não por acaso, passa a ser mais contundente a partir das décadas de 1960 e 1970, coincidindo justamente com a entrada em cena desses e outros protagonistas. "Riqueza", "interculturalidade", "diversidade", "miscigenação", entre outras, são noções que se definem pela valorização do "popular" (festas, religiões, costumes, folclore cultivado, principalmente, por descendentes de "negros" e "índios").

\section{A afirmação de um "patrimônio cultural"}

Se São Luís herdou do século XIX, no campo intelectual o honroso epíteto de Atenas Brasileira devido ao destaque alcançado a nível nacional de inúmeros intelectuais, no campo arquitetônico, a herança foi um conjunto de edificações em estilo colonial, que denotavam a imponência de um período de prosperidade material, com casarões e suas fachadas revestidas em azulejo. (Silva, 2009: 63)

O "centro histórico" de São Luís do Maranhão recebeu, em 1997, o título de Patrimônio Mundial, conferido pela União das Nações Unidas para Educação, a Ciência e Cultura (UNESCO). Tal consagração da arquitetura colonial como patrimônio material da humanidade encerra uma série de disputas e estratégias políticas e culturais, empreendidas em vários níveis e que são reveladoras de princípios subjacentes aos processos contemporâneos de patrimonialização. 
Para o momento, o foco recai sobre alguns investimentos "intelectuais" e institucionais que levaram à apreciação das "construções coloniais" como bens marcados por um sentido de raridade (vestígios excepcionais de uma "época") e de exemplaridade (manifestação de um padrão e de um estilo de vida valorizados). Haja vista que, após o momento inaugural de "desenvolvimento urbano, econômico e arquitetônico", o "tecido urbano do centro antigo" de São Luís teria se "degradado" e sua arquitetura sofrido desqualificações (Silva, 2009: 65).

Um dos argumentos dessa decadência e, consequentemente, da necessidade de restauração, consiste em afirmar que o "decréscimo do comércio" e a "saída das famílias abastadas" para outros bairros, o antigo centro teria sido ocupado por "pessoas oriundas das camadas menos favorecidas" (ibidem: 66). Somar-se-ia a isso a confluência entre um discurso sanitarista em voga e, particularmente a partir dos anos 1930, de um discurso do progresso, que levavam à desvalorização das moradias e da "arquitetura colonial". O que teria interferido para que as "iniciativas do poder público [fossem] orientadas para construção da moderna sede do Estado" (Lopes, 2008: 29, apud Silva, 2009: 68) e que se investisse em uma "obra de remodelação e reforma urbanística da velha cidade" (Diário Oficial, de 01 de março de 1935, apud Silva, 2009: 69).

No entanto, no final da mesma década, já existiam, também, vozes laudatórias à "arquitetura portuguesa", não por acaso registradas e ativadas justamente por agentes e instâncias que têm sua existência vinculada à institucionalização de uma ideia de "patrimônio".

Interessado, desde o início de suas atividades como pesquisador, pelos vestígios de nosso passado, Raimundo Lopes ${ }^{14}$ afirmaria, em 1937, que 'a história dos fortes e outras antigalhas do Maranhão é interessantíssima; sobre ela escrevemos alguns artigos. (Sphan, 1937: 83, apud Silva, 2009: 78)

Em 1937, mostrando-se sintonizado com as iniciativas dos intelectuais e gestores da administração federal, Raimundo Lopes marca presença no primeiro número da Revista do SPHAN, no ano de sua criação, como o texto 'A Natureza e os Monumentos Culturais', onde traça um panorama das cidades históricas da época e defende a proteção aos sítios arqueológicos na Ilha de São Luís, os sambaquis, listando, ao final, dez requisitos gerais para a preservação. (Lopes, 2004: 63-64, apud Silva, 2009: 79)

A efetivação de políticas públicas direcionadas ao "conjunto arquitetônico" do atual "centro histórico" de São Luís ocorrera desde a década de 1970. Em 1979, foi realizado pelo governo do estado o Primeiro Encontro Nacional da Praia Grande (principal bairro, próximo ao porto, anteriormente centro comercial ocupou um cargo de coordenação de evento, bem como atuou no Centro de Artes Cênicas do Maranhão (CACEM), também durante a gestão de Tácito Borralho como diretor (até 2003). Ocupou igualmente o cargo de Superintendente de Ação e Difusão Cultural na Secretaria de Cultura do Maranhão, durante a gestão do petista João Ribeiro (20072009) (Entrevista com Josias Sobrinho, realizada em 23/06/2009).

13. Tácito BorraIho é teatrólogo, diretor de teatro e professor mestre da UFMA na área de artes cênicas. Entre as suas inserções, cabe mencionar a fundação do Laboratório de Expressões Artísticas, que teria sido "um movimento político camuflado, era artístico politizado" (entrevista com Tácito Borralho). Foi professor de história, geografia, francês, português, filosofia no ensino médio. Professor de pós-graduação na especialização nas técnicas de animação de bonecos de varas gigantes. Foi coordenador de Ação e Difusão Cultural na Secretaria Estadual de Cultura (1983-1990); presidente da Federação Nacional de Teatro Amador; da 
Confederação $\mathrm{Na}$ cional de Teatro Amador, da Associação Brasileira de Teatro de Bonecos e do Centro Unima Brasil. Foi diretor do Centro de Artes Cênicas do Maranhão (1990-2003), diretor do Teatro João do Vale (1997-1999), entre outras coisas. (Entrevista com Tácito Borralho, realizada em 15/06/2009).

14. "Raimundo Lopes (1894-1941) é natural da cidade de Viana, no interior do estado do Maranhão. Sua formação acadêmica foi em Letras. Fez diversos estudos nas áreas de: história, sociologia e questões arqueológicas [...] foi um colaborador do órgão federal gestor do patrimônio, que a partir da década de 1940 com as diversas atuações de proteção a bens considerados patrimoniais, colabora para ser edificado um novo olhar das autoridades públicas locais." (Silva, 2009: 78-79)

15. "Ronald Almeida Silva é arquiteto e planejador urbano regional. Graduado pela FAUUFRJ (1972), com pós-graduação em Planejamento Urbano e Regional pela Faculdade de Ciências Sociais da Universidade de Edimburgo, Escócia (1983). Consultor 'ad hoc' da Unidade Executora do PRODETUR, do Projeto e residencial, atualmente centro histórico e cultural da capital). Tratava-se de "discutir o desenvolvimento urbano de São Luís", visando "avaliar a proposta de revitalização do Centro Histórico de São Luís, elaborada pelo arquiteto John Gisiger" (Souza, 2002: 59, apud Silva, 2009: 92). O americano, arquiteto formado pela Cronell University dos EUA, havia catalogado e classificado os "monumentos históricos". Então, juntamente com Luís Philipe Andrés e Ronald Almeida Silva ${ }^{15}$, constituiu, a partir do Encontro, o grupo de trabalho que produziu o Projeto de Preservação e Revitalização do Centro Histórico de São Luís, "instituído a partir do Decreto $n^{\circ} 7.345$ (16/11/1979), também conhecido como Projeto Praia Grande/Reviver" (Aires, 2007: 151; apud Silva, 2009: 93).

De 1979 a 1982, ocorreu a idealização do Projeto e o início das "intervenções urbanísticas no sítio histórico" e, de 1983 a 1987, "por ausência de recursos, foram interrompidas as obras" (Andrés apud Silva, 2009: 97), o que teria levado os responsáveis a investirem na realização de pesquisas ${ }^{16}$.

No período em que o atual senador maranhense José Sarney foi presidente da república (1985-1990), o governo do Maranhão esteve sob a administração de outro aliado seu: Epitácio Cafeteira Afonso Pereira (1987-1990) ${ }^{17}$. Contando com verbas do Ministério da Cultura ${ }^{18}$ e da Secretaria de Cultura do Maranhão (SECMA), nesse momento foi retomado o "projeto de restauração" do "centro histórico".

Em 1986, ocorrera o tombamento de uma área que abrangia e extrapolava a área que havia sido tombada pelo Governo Federal, em 1974. Igualmente nesse ano foi criada a Comissão do Patrimônio Histórico de São Luís, cuja atribuição seria de "analisar as políticas públicas para o Centro Histórico" (ibidem: 98). Principalmente a partir de 1987 houve "uma retomada dos investimentos no bairro da Praia grande, que foi inteiramente recuperado" (ibidem). O então governador, que visava imprimir uma "marca pessoal" ao "projeto de revitalização e preservação", modificou o nome do "Projeto Praia Grande" para "Projeto Reviver". O "programa de obras" foi prosseguido durante o governo seguinte de Edison Lobão (1991-1994).

Esse percurso de investimentos foi maximizado na administração de Roseana Sarney (1995-1998), notadamente com o fortalecimento dos projetos que desencadearam a proposição da inclusão da cidade de São Luís na lista do Comitê do Patrimônio Mundial da UNESCO. Seu secretário de cultura à época era Eliéser Moreira Filho.

Filho de um ex-deputado que ocupou vários cargos técnicos em administrações nacionais e locais (Piauí) relacionados à sua formação como Engenheiro Agrônomo, Eliéser Moreira Filho foi, em 1966, nomeado pelo 
governo estadual de José Sarney para chefiar a Superintendência do Desenvolvimento do Maranhão (Sudema). Em 1967, foi secretário estadual de Administração e também de Reforma Administrativa. Tendo sido ainda Chefe da Casa Civil em 1969, elegeu-se deputado estadual pela Arena em 1970. Entre 1975-77 assumiu a Superintendência de Melhoramentos de São Luís. Em 1977 e 1978 ocupou a presidência do Serviço de Planejamento da Secretaria de Modernização da Reforma Administrativa, em Brasília, e a coordenação de área da Secretaria de Planejamento (até 1982). Em 1979 filiou-se ao PDS e iniciou o curso de Pós-Graduação em Administração Pública na Fundação Getúlio Vargas, em Brasília, concluído em 1981. Foi nomeado coordenador de área do Programa Grande Carajás, de 1982 à 1983; secretário de Indústria e Comércio no governo de Luís Rocha, em 1983; assumiu a Secretaria de Administração, em 1983, onde ficou até 1986, sendo que, desde 1985, filiado ao PFL. Elegeu-se deputado federal, em 1986, com o apoio de Roseana Sarney e contando com o fato de José Sarney ser presidente (1985-1990). Com a instalação da Assembléia Nacional Constituinte, foi titular da Subcomissão dos Municípios e Regiões, da Comissão da Organização do Estado e suplente da Subcomissão da Política Agrícola e Fundiária e da Reforma Agrária, da Comissão da Ordem Econômica. Em 1991 foi secretário-chefe da Casa Civil no governo de Edson Lobão e diretor administrativo do Banco do Estado do Maranhão de 1992 à 1994. Em 1995 tornou-se secretário estadual de Cultura do primeiro período do governo de Roseana, até 1998, quando assumiu a Secretaria de Estado de Articulação Política para trabalhar pela reeleição da governadora. Em 1999 participou da reforma administrativa que transformou as secretarias em gerências estaduais, tendo sido nomeado para a de Desenvolvimento Regional de Caxias, no interior do estado. (Dicionário Histórico-Biográfico Brasileiro. Rio de Janeiro: Editora FGV; CPDOC, Vol. IV, 2001: 3914-3915).

Luís Phelipe Carvalho de Castro Andrès, desde 1980, desempenha atividades que o credenciariam a dizer o que é a "arquitetura" do Maranhão e como e porque esta se constituiria num "patrimônio" cujo reconhecimento jurídico seria apenas uma atestação.

Com mestrado em Desenvolvimento Urbano (Centro de Conservação Integrada/CECl da Universidade Federal de Pernambuco, 2006), pertenceu ao Conselho Consultivo do IPHAN - Instituto do Patrimônio Histórico e Artístico Nacional (desde 2000) e ao Conselho Nacional de Política Cultural do Ministério da Cultura (desde 2007). Também "é diretor (cargo comissionado sem vínculo empregatício) do Centro Vocacional Tecnológico Estaleiro Escola do Maranhão, vinculado à Universidade Virtual do Estado do Maranhão - UNIVIMA, atuando principalmente nos seguintes temas:
Praia Grande/Reviver e da Coordenadoria do Patrimônio Cultural da Secretaria de estado da Cultura. Coordenador Geral (1980-1981) e Coordenador Administrativo (19841985) do Projeto Praia Grande. Secretário Municipal de Urbanismo de São Luís (19861988). Membro da Comissão Técnica de Coordenação do Projeto Revivier (1988-1989). Subsecretário do Codema/SEPLAN-MA (1991-1992). Secretário de estado da Indústria e Turismo (1993-1994). Diretor presidente da Usina Siderúrgica do Maranhão (1995-1997)." (Silva, 2009: 127)

16. Foram realizadas pesquisas tais como: "pesquisa socioeconômica da população residente no Centro Histórico; Projeto de Microfilmagem e Transcrição Paleográfica dos Livros da Câmara de São Luís dos séculos XVII, $X V I I$ e XIX, em convênio com o CNPq, sendo descobertos 166 volumes dos Livros de Câmara de São Luís (arquivos do Conselho Municipal) de 1646 a 1900 , antes considerados perdidos; Projeto Embarcações do Maranhão, através do convênio FINEP/SEPLAN$M A$, no intuito de recuperar técnicas de construção navais artesanais do 
Estado; Projeto Sítio do Físico, também através do convênio FINEP/SEPLAN-MA, visando garantir salvaguarda do conjunto de ruínas de arqueologia histórica." (Andrés, 1998, apud Silva, 2009: 97)

17. Rival da "família Sarney", Jackson Lago (PDT) foi prefeito da capital entre 1982 e 1992. Mesmo tendo criado a Fundação de Cultura da Cidade visando "atender a população que exigia maiores investimentos da prefeitura na limpeza da cidade, na recuperação de prédios históricos e no apoio a manifestações populares" (Cardoso, 2008: 96), não conseguiu rentabilizar a paternidade dos empreendimentos de (auto) consagração de um "patrimônio histórico".

18. O Ministério da Cultura foi instituído durante o governo de José Sarney na Presidência da República: "Até então, a cultura era gerida em conjunto com a educação, pelo $\mathrm{Mi}$ nistério da Educação e Cultura. Segundo o decreto $n^{\circ} 91.144$ a emergência do $\mathrm{Mi}$ nistério da Cultura obedecia à situação do Brasil à época, que não podia prescindir de uma 'política nacional de cultura, condizente com os novos tempos e com o desenvolvi- preservação do patrimônio cultural, história da técnica/embarcações tradicionais". Foi chefe do setor de Pesquisa e Documentação do Programa de Preservação e Revitalização do Centro Histórico São Luís (1980-1981); coordenador Administrativo do Programa Preservação e Revitalização do Centro Histórico São Luís (1983-1984); coordenador Geral do Programa de Preservação e Revitalização do Centro Histórico (1984-1989); membro do Conselho de Cultura do Estado do Maranhão (1989-1999); presidente do Conselho de Cultura do Estado do Maranhão (1992-1994); presidente do Conselho Estadual de Cultura do Maranhão (1993-1994), superintendente do Patrimônio Cultural do Estado do Maranhão (1996-2006). Até fevereiro de 2001, funcionário da Companhia Energética do Maranhão - CEMAR, trabalhando à disposição do Governo do Estado como Coordenador do Programa de Preservação e Revitalização do Centro Histórico de São Luís. A partir de 2001 ocupou cargos comissionados no âmbito da administração estadual sem vínculo empregatício. Coordenou o Programa de Preservação chamado, inicialmente de "Projeto Praia Grande" e depois "Projeto Reviver". Em 1996, coordenou a equipe que elaborou o relatório técnico que deu origem ao dossiê apresentado à UNESCO que apresentava São Luís como capital Patrimônio Mundial. Afora alguns artigos, possui três livros publicados com os seguintes títulos: "Centro Histórico de São Luis. Patrimônio Mundial”; "Embarcações do Maranhão - Recuperação das Técnicas Construtivas Tradicionais Populares" e "Monumentos históricos do Maranhão" (Fonte principal: Plataforma Lattes/CNPq).

No Perfil Artístico e Cultural do Maranhão, Andrès (2006) estabeleceu a gênese das construções arquitetônicas no Maranhão (século XIX) até a conquista do título de "Patrimônio Mundial da Humanidade". Uma vez apresentado o cenário que certifica, ao mesmo tempo, a matéria prima e o resultado do seu trabaIho, dedicou-se a retomar o histórico de preservação ou de proteção jurídica do "acervo arquitetônico e paisagístico a nível federal, estadual e municipal". Aqui, a categoria "patrimônio" emerge vinculada às estratégias de tombamento levadas a cabo pelo Instituto de Patrimônio Histórico e Artístico Nacional (IPHAN) que garantiria, por Decreto, a proteção estadual às construções certificadas. No nível municipal, é mencionado o Plano Diretor Urbanístico de 1992, que dividiu a "Zona de Preservação Histórica (ZPH) e Zona de Preservação Ambiental". O "patrimônio", oficialmente reconhecido como tal, exigiria "uma política de preservação e revitalização, a fim de melhor estruturar essa área e promover o desenvolvimento da cidade de São Luís". Ter-se-ia, então, as condições favoráveis para a implementação do "Programa de Preservação e Revitalização do Centro Histórico de São Luís". O "coroamento" desses investimentos fora a conquista do título de São Luís como "Patrimônio Mundial da Humanidade". Assim, a consagração jurídica e estatal, nacional e internacional é acionada como caução, 
pois sanciona e santifica a "arquitetura" e a "paisagem" com o valor de "acervo" e de "patrimônio".

Um dos projetos coordenados por Andrés foi o denominado "Viva Madre Deus" (1997-1999), que vislumbraria a "valorização da cultura popular" mediante a reforma deste "bairro que reúne diversas manifestações das culturas populares em São Luís" (Cardoso, 2008: 92). Próximo ao então "centro histórico", a "estratégia de implementar a infraestrutura do bairro" confluía com a perspectiva de transformar a capital em "Patrimônio da Humanidade" (ibidem). A iniciativa compatibilizava-se com a relevância que a "cultura popular" detinha e que fora reforçada na agenda pública com a gestão de Luís Henrique Bulcão na Secretaria de Cultura, durante o segundo governo de Roseana Sarney.

Luis Henrique de Nazaré Bulcão nasceu em 1949, em São Luís do Maranhão, no bairro Madre Deus, localizado no centro da cidade e considerado um dos mais boêmios e "ricos" em termos de criação e manifestação cultural (são provenientes de lá produtores e porta-vozes da "cultura popular" do estado). Aposentado como Auditor da Receita Federal, é advogado, compositor, poeta e produtor cultural. Foi membro do grupo Unidos do Regional Tocado a Álcool (URTA), em 1975, é sócio-fundador da Companhia Barrica (1985), que se constitui do Boizinho Barrica, Bicho Terra e a Natalina da Paixão. Compôs uma série de canções para a Companhia e é autor de músicas de vários grupos carnavalescos maranhenses. Além de intérpretes locais, tem canções gravadas por artistas conhecidos nacionalmente, como Leci Brandão, Durval Lelis, Pathanca, Célia Maria e Alcione Nazareth. Foi secretário de Cultura durante o governo de Roseana Sarney (1998 a 2001) e, em 2002, na gestão do governador José Reinaldo Tavares. Com a cassação do mandato de Jackson Lago e a posse de Roseana Sarney como governadora, Bulcão está novamente à frente da Secretaria de Cultura (desde 2009).

Nessa fase, destaca-se, fundamentalmente, o papel do Centro de Cultura Domingos Vieira Filho (CCDVF), órgão subordinado à Superintendência de Cultura Popular do Maranhão, da Secretaria de Estado da Cultura, e à Comissão Maranhense de Folclore (CMF), que serão tratados mais adiante.

Agentes com outros perfis e domínios de inserção contribuem para a celebração do "patrimônio" como uma questão social relevante, como é o caso dos pesquisadores das ciências humanas e sociais que se debruçam sobre essa temática. No Maranhão, pode-se destacar pesquisas que vêm sendo realizadas nas áreas de antropologia e história, que combinam referenciais acadêmicos com discussões normativas que permitem aos agentes acumularem recursos passíveis de serem reconvertidos para os domínios burocráticos e administrativos de gestão mento já alcançado pelo país". (Cardoso, 2008: 73 ) 
do "patrimônio cultural".

Há também que se mencionar a importância da atuação de agentes vinculados a órgãos federais, como o Instituto de Patrimônio Histórico e Artístico Nacional (IPHAN), no sentido não somente da "preservação" e "proteção" do "patrimônio material e imaterial", mas também da transmissão de um "legado comum". Ilustra-se com a matéria abaixo, realizada com a dirigente da Superintendência Regional do IPHAN no Maranhão, em que reivindica uma "educação patrimonial nas escolas":

Sergipana de nascimento, maranhense do coração. Casada, mãe de dois filhos - um rapaz de 23 anos e uma jovem de 20 anos - a historiadora Kátia Bogéa dedicou sua vida inteira à proteção ao patrimônio cultural do Brasil do Maranhão (...) ela falou sobre a paixão por São Luís e os desafios do Instituto Nacional do Patrimônio Histórico e Artístico do Maranhão (Iphan). Você acha que a população tem noção do peso que é esta preservação patrimonial para suas vidas? Veja, o processo de tombamento de São Luís começou na década de 40, do século XX. Nessa época ocorreram os primeiros tombamentos federais. O tombamento em conjunto de São Luís foi em 1974. Já Alcântara foi tombada inteira em 1948. E São Luís foi reconhecida como Patrimônio Mundial em 1997. É muito tempo. Acho que o trabalho feito com a comunidade, em relação à educação patrimonial, não foi efetivo o suficiente, deixa muito a desejar. Tem que estar nas escolas, na formação das crianças que têm que compreender e ter instrumentos de decodificação para saber o que significa esse patrimônio para suas vidas. Só assim elas vão protegê-lo. Ninguém protege aquilo que não conhece, então é preciso levar essa informação. (http://www. oimparcial.com.br/noticias. php?id=11042, acessado em 20/08/2009)

Com efeito, a valorização do "patrimônio arquitetônico" é resultado de um trabalho social de invenção, nos quais os agentes, ao construírem e confrontarem versões de e do "patrimônio" (comum e coletivo), podem incrementar seus patrimônios pessoais, beneficiando-se pela detenção da autoridade legítima de defini-lo e galgando posições socialmente reconhecidas em seu nome. Seria preciso investigar com maior cuidado os diferentes sentidos disputados por "especialistas" localizados em pontos diversificados do espaço social, levar em conta os estados das disputas que travam, bem como a distribuição das armas (recursos) e dos interesses (sem juízo de valor) que possuem.

\section{A propósito da "cultura popular"}

No Maranhão, "cultura popular" e "folclore" são temas que "revestem-se de singular complexidade, pois, desde os anos 1970, as políticas públicas munici- 
pais e estaduais de cultura e de turismo elegeram as manifestações folclóricas como foco de atenção" (Cavalcanti, 2009: 199). Mais do que isso, os investimentos nesse sentido incidiram no caráter da institucionalização das ciências sociais no estado, tributária das pesquisas inaugurais de folclore em diferentes estados, como é possível observar na atuação do Movimento Folclórico Brasileiro (19471964), cujos integrantes - "intelectuais das elites locais" - conformavam "redes de relações extremamente eficientes" (ibidem: 200). Por esse intermédio, teriam estimulado as buscas, registros e estudos das "manifestações folclóricas", do mesmo modo que teriam contribuído para a afirmação da "preocupação com o que hoje chamaríamos de sua inclusão nas políticas públicas de cultura: tratava-se de mobilizar a consciência cidadã com congressos, semanas, encontros; de apoiar os grupos praticantes; de criar museus e centros de referência" (ibidem: 201).

O encontro entre Sérgio Ferretti com o "intelectual" maranhense Domingos Vieira Filho teria sido imprescindível para a consolidação do tema "folclore" nas pesquisas universitárias e na criação de instâncias específicas para a sua gestão.

Domingos Vieira Filho, nascido em São Luís no dia 25 de setembro de 1924, foi advogado, escritor e jornalista, tendo atuado com destaque como administrador cultural e pesquisador da cultura popular maranhense. Formado pela Escola de Direito de São Luís, lecionou no Liceu Maranhense (tradicional escola pública da cidade), na Escola Técnica de Comércio Centro Caixeiral e na Academia do Comércio. Foi, também, professor de nível superior, contribuindo com a formação de alunos da Faculdade de Serviço Social, Faculdade de Filosofia e Departamento de Direito da Universidade Federal do Maranhão. Como administrador cultural, demonstrou competência realizando importante trabalho como membro do Conselho Estadual de Cultura, delegado do Serviço de Patrimônio Histórico e Artístico Nacional, diretor do Teatro Arthur Azevedo e do Departamento de Cultura da Secretaria de Estado de Educação e como presidente da Fundação Cultural do Maranhão de 1975 a 1979, quando reestruturou o Arquivo Público do Estado e viabilizou a criação do Museu Histórico da cidade da vizinha Alcântara. Em sua vida profissional ocupou cargos de consultor técnico do Diretório Regional de Geografia e conselheiro técnico da Federação do Comércio. Sua produção bibliográfica registra contribuições para a cultura maranhense. Publicou diversos livros, dentre os quais destacam-se: A Linguagem Popular no Maranhão, Superstições ligadas ao Parto e à Vida Infantil, A Festa do Divino Espírito Santo, Folclore Sempre, Populário Maranhense e Breve História das Ruas e Praças. É, também, autor de Os Negros Deformados, O Negro na Poesia Brasileira, A Síntese Histórica da Polícia Militar do Maranhão e Estudos Geográficos do Maranhão. (http://www.culturapopular.ma.gov.br/biografias2.php?id=5, acessado em 05/11/2009) 
19. Além dos resultados favoráveis da parceria entre Domingos Vieira Filho e Ferretti no "cenário político institucional maranhense", Cavalcanti (2009) sublinha a relevância do "contexto de reorganização institucional da área federal da cultura pelos governos militares". Ou seja, trata-se de um momento em que há (em 1976): “o surgimento da Fundação Nacional de Arte (FUNARTE), vinculada à Secretaria de Cultura do então Ministério de Educação e Cultura (MEC), e data de 1979 a transformação da antiga Campanha de Defesa do Folclore (INF) como unidade vinculada à FUNAR$T E$, sob gestão de Bráulio Nascimento. Nesse novo contexto, a antiga rede nacional de folcloristas, tecida entre os anos 1940 e 1960, será acionada e resignificada" (ibidem: 216).
Sergio Ferreti, nascido no Rio de Janeiro, passou a residir definitivamente no Maranhão em 1970, lecionando na Escola de Administração, atual Universidade Estadual do Maranhão e depois na Universidade Federal do Maranhão. Atuou na Superintendência de Ensino e colaborou na formulação do projeto (por volta de 1968) que deu origem ao curso de Ciências Sociais da UFMA que, no entanto, só foi efetivado em 1986, com o fim do regime militar. Sendo formado em História (UB/UFRJ - 1962) e museologia (MHN/UniRio - 1962), se dedica ao estudo da antropologia e à sistematização de um projeto de pesquisa sobre cultura popular e folclore no Maranhão. Durante os anos 1960 estudou na Bélgica e participou do Centro de Estatísticas Religiosas e Investigações Sociais (CERIS/RJ), da Conferência Nacional dos Bispos Brasileiros (CNBB). Ferretti pertenceu à Juventude Universitária Católica (JUC) e do Movimento de Educação de Base (MEB), através do qual se deslocou para o Maranhão pela primeira vez, em 1963. Em depoimento no livro Memória de Velhos (TEIXEIRA, 2008), ele declara que tinha uma "vocação religiosa, o desejo de entrar no Mosteiro - acho que era mais uma atração intelectual, porque eu sentia ali um ambiente intelectual muito elevado, um ambiente de arte, literatura, música. Sentia uma grande admiração por esses aspectos" (ibidem: 112). Influenciaram no estudo das "religiões afro-brasileiras, tambor de mina, Casa das Minas, cultura popular, tambor de crioula e sincretismo" (...) "a relação com Vieira Filho, o contato com a obra de Roger Bastide e também o estímulo do pai de sua esposa Mundicarmo Ferretti que "escrevia e se interessava muito por folclore (...)" (ibidem: 136). No final do ano de 2009 foi condecorado como Professor Emérito da UFMA. (descrição elaborada a partir de duas fontes principais: currículo lattes e Teixeira (2008)).

Pode-se destacar a criação, em 1973, da Fundação Cultural do Maranhão (FUNC) e o início da organização do Museu Histórico e Artístico do Maranhão. Em 1975, a FUNC fora "ampliada" e Domingos Vieira Filho assumiu a sua presidência, convidando Ferretti para dirigir o Departamento de Assuntos Culturais ${ }^{19}$. Com o falecimento de Vieira Filho na década de 1980, o seu nome foi dado ao Centro de Cultura Popular.

Os diretores do Centro e outros agentes da "cultura popular" foram chamados por Ferretti para compor a reativação da Comissão Maranhense de Folclore (outrora subcomissão na qual Domingos Vieira Filho representava o estado na Comissão Nacional de Folclore), cujos objetivos seriam:

(...) colaborar com o Centro de Cultura Popular do Maranhão e com as Secretarias de Cultura, de Educação, de Turismo, com Fundações, Universidades, Academias e com outras entidades culturais interessadas em pro- 
mover, divulgar e pesquisar o folclore e a cultura popular no Maranhão. (Ferretti, 2006: 166)

Dentre os investimentos dessas instâncias, pode-se grifar o livro Memória de Velhos. Depoimentos. Uma contribuição à memória oral da cultura popular maranhense (depoentes: Aliete Ribeiro de Sá, Carlos de Lima, Sergio Ferretti, Therezinha Jansen e Zelinda Lima), produzido pela CMF, cuja presidente era, no período da publicação, Maria Michol Pinho de Carvalho, que à época também ocupava o cargo de Superintendente de Cultura Popular, vinculado à Secretaria de Cultura ${ }^{20}$.

Mestre em Comunicação Social, com área de concentração em Comunicação e Cultura Popular, Maria Michol Pinho de Carvalho atua na Secretaria de Cultura do Maranhão desde 1987. Foi Superintendente de Cultura Popular da Secretaria de Estado da Cultura, diretora do Centro de Cultura Popular Domingos Vieira Filho e, desde 1995, é presidente da Comissão Maranhense de Folclore.

O trecho abaixo foi extraído da introdução do livro:

As lembranças do passado bem como demonstram a herança recebida que precisa ser complementada com o toque do presente numa dinâmica que por vezes se constitui num verdadeiro desafio. Aí está justamente a necessidade e a importância do registro escrito destes cinco depoimentos, no sentido de que as informações, comentários e opiniões presentes nos seus conteúdos são valiosas para a compreensão de todo um jeito de ser da gente maranhense (...). (p. 15)

No texto que consta na orelha do livro, elaborado por uma antropóloga e reconhecida pesquisadora da "cultura popular", Mundicarmo Ferretti (esposa de Sérgio Ferretti), a ênfase recai sobre a importância dos mais "velhos" como "elo de comunicação com o passado e que, se cada geração conseguir passar às outras um pouco de sua experiência, podemos confiar no futuro". Ela ainda classifica os depoentes em: 1) "produtoras de cultura popular"; 2) dirigente de órgãos estaduais das "áreas de cultura e turismo"; 3) e, pesquisadores, "analistas perspicazes da cultura popular maranhense" e ex-presidentes da Comissão Maranhense de Folclore.

Mundicarmo Ferretti possui o título de Professor Emérito da UEMA. Possui graduação em Filosofia, Licenciatura pela Universidade Federal do Maranhão (1966), mestrado em Administração Pública (Pessoal) pela Fundação Getúlio Vargas - RJ (1975), mestrado em Ciências Sociais (Antropologia) pela Universidade Federal do Rio Grande do Norte (1983) e doutorado em Ciências - Antropologia Social pela Universidade de São Paulo (1991). É

20. Trata-se do sexto volume da série de sete livros coordenados por Maria Michol Pinho de Carvalho. Os quatro primeiros volumes foram publicados em 1997, o quinto em 1999, o sexto em 2006 e o sétimo em 2008. 
professora titular aposentada da Universidade Estadual do Maranhão UEMA (2002), professora adjunta IV aposentada da Universidade Federal do Maranhão - UFMA (1992). Atualmente é professora permanente dos Programas de Pós-Graduação em Políticas Públicas (Dr e MS) e de Ciências Sociais (MS) da UFMA; Sub-coordenadora do Grupo de Pesquisa "Religião e Cultura Popular" - GPMINA - DESOC/UFMA [coordenado por Sérgio Ferretti]; membro titular da Associação Brasileira de Antropologia - ABA, da Comissão Maranhense de Folclore - CMF, e Secretária-administrativa do Instituto Nacional da Tradição e Cultura Afro Brasileira - INTECAB-MA - Tem experiência de ensino e de pesquisa na área de Antropologia, com ênfase em Antropologia das Populações Afro-Brasileiras, atuando principalmente nos seguintes temas: religião afro-brasileira, tambor de mina, pajelança de negro, sincretismo, cultura popular e Maranhão. (currículo lattes/CNPq)

Do mesmo modo, são os objetivos explicitados no Perfil Artístico e Cultural do Maranhão, em que Maria Michol Pinho de Carvalho foi a consultora responsável, o "resgate", a "documentação" das "tradições culturais e artísticas no Maranhão" com vistas a "consolidar informações e registros das manifestações culturais locais, assegurando a sua preservação e transmissão para as próximas gerações" (Carvalho, 2006, s/p).

"Diversidade de heranças e tradições", eis a síntese que definiria a "cultura popular" defendida e compartilhada por outros dos seus porta-vozes. As festas e os rituais cultivados no estado seriam a atestação das "formas peculiares de expressão" e "elementos de distinção" que edificariam a "identidade cultural maranhense", calcada nas "origens dos negros" e da "cultura afro" que "articularam-se e misturaram-se com modos de vida dos portugueses e dos indígenas":

(...) [a] cultura popular maranhense, em sua riqueza e diversidade, encarna processos de integração, assimilação e sincretismo em meio à resistência de grupos e à intervenção das elites", o que a definiria pela sua "peculiar expressão da natureza 'mestiça da cultura brasileira' que foi se constituindo nas adaptações, assimilações e trocas culturais". Adiciona que "nesses processos de confrontos e de encontros constitutivos da cultura maranhense, a influência afro-brasileira é marcante e decisiva. Com efeito, nas práticas religiosas, nas danças, na literatura, no teatro, na culinária, na medicina popular e nos costumes e usos, os africanos e seus descendentes conseguiram, aqui no Maranhão, recriar suas culturas de origem, constituindo uma espécie de síntese dos elementos culturais. (Carvalho, 2006, s/p)

O "calendário da cultura popular maranhense" expressaria a cristalização do 
trabalho de produção da existência daquilo que enuncia.

A "dinâmica da vida social" é apresentada a partir do desdobramento de "três grandes ciclos": o ciclo carnavalesco, o ciclo junino e o ciclo natalino, afora outras "festas tradicionais", como a festa em homenagem ao "Divino espírito Santo", e as "danças que têm a peculiaridade de realizar-se em diferentes momentos do ano, integrando mais um ciclo cultural. É o caso do 'tambor de crioula, dança de origem africana em homenagem a São Benedito, o 'santo negro' da religiosidade popular".

O carnaval é concebido como o primeiro ciclo e como constituído de três fases fundamentais: 1) o "Carnaval Colonial" (predominante até o século XIX); 2) o "Carnaval dos Cordões" (característico das primeiras décadas do século XX); e 3) o "Carnaval do Samba" (a partir da segunda metade do século XX). Se os primeiros são sempre alvo de recordações nostálgicas, os últimos acabariam despertando enfrentamentos entre os defensores e os críticos da "importação" de um "padrão carioca". Confrontos esses que teriam resultado em um "novo momento de resgate da tradição", graças à "intervenção ativa de um movimento cultural que, estrategicamente, colocou na agenda pública o carnaval de rua maranhense".

Conforme Carvalho (2006), no decorrer da década de 1990, iniciativas lideradas por dirigentes de órgãos comprometidos com a "cultura popular maranhense" resultaram, por exemplo, na mobilização de "lideranças, artistas e dirigentes das organizações carnavalescas" visando "fazer renascer o Carnaval de Rua em São Luís". O produto desta mobilização, em termos de políticas públicas, teria sido:

- institucionalização do Circuito de Carnaval de Rua Deodoro/Madre Deus/ Deodoro, com decoração e sonorização dentro do espírito da época. É o circuito da folia onde se apresentam os blocos e brincadeiras, (re)vivendo o "jeito maranhense de brincar o carnaval";

- programação carnavalesca nos "Vivas" dos bairros, (re)atualizando a tradição com apresentação de blocos e brincadeiras e de shows, (re)criando, nas comunidades, o espírito carnavalesco e estimulando a emergência dos "blocos de sujos" onde "o povo cai na folia" do jeito que lhe sugere a sua criatividade e a sua imaginação;

- apoio financeiro aos blocos e às brincadeiras para que possam vir a público com suas fantasias e sons peculiares;

- experiências de resgate de elementos da tradição viabilizadas pelo Centro de Cultura Popular Domingos Vieira Filho, em parceria com a Comissão Maranhense de Folclore. São oficinas, exposições, cortejos carnavalescos, apresentação de grupos do interior do Estado, bailes populares etc. (Carvalho, 2006). 
As mesmas lógicas e princípios agilizados para descrever o "carnaval" são utilizados para consagrar a "cultura" e as "políticas culturais" no estado a partir do "ciclo junino". Quer dizer, em que

(...) os arraiais ou largos, hoje, continuam a funcionar, como herança de uma tradição que se ressignifica, assumindo as marcas dos novos tempos, articulando a dimensão popular da festa com o incentivo e apoio oficial, nomeadamente no patrocínio das apresentações e da infra-estrutura básica. (ibidem)

A importância do favorecimento (institucional) e reconhecimento social do valor das apresentações de bumba-meu-boi é fortalecida pelo sentido de "diversidade" (tão caro para a construção da identidade maranhense) que ele permite ativar e, também, por seu itinerário de exclusão e superação. Isto é, não raro, na reconstituição da história das "brincadeiras", é ressaltado que, na segunda metade do século XIX, eram proibidas as apresentações que, depois, foram permitidas, mas dentro de muitas restrições. E, na primeira metade do século vinte, ainda seriam estigmatizados pela "sociedade maranhense".

Finalmente, no que diz respeito ao "ciclo natalino", este se sustentaria no fato de que "o maranhense é um povo muito ligado à religião, o que pode se constatar com facilidade ao verificar o calendário religioso da capital aos mais longínquos municípios do Estado". Nesse caso, são sublinhadas diferentes festas religiosas, como a festa do Divino Espírito Santo, em que são celebrados "os mais diversos santos da Igreja Católica".

\section{Notas Finais}

Tanto o "patrimônio cultural" como a "cultura popular" são categorias cujos sentidos são variáveis e construídos conforme as relações e os conteúdos jogados em dinâmicas específicas. No primeiro caso, os princípios subjacentes aos discursos que ressaltam a importância da valorização, "restauração", "revitalização" - entre outras expressões que indicam a necessidade de agir sobre e em nome de um "patrimônio" - são complexas e reveladoras de estratégias de consagração que, em absoluto, restringem-se, essencialmente, aos "monumentos", à "cultura", à "memória", etc. Tais princípios emergem das diferentes posições ocupadas (nos domínios específicos e no espaço social em geral) e posicionamentos defendidos (versões, interpretações, descrições, etc.) pelos agentes que desempenham os papéis de porta-vozes e mediadores culturais. Sendo assim, esses "especialistas", situados em arenas específicas, acionam suas "competências" nos embates pelo monopólio do saber legítimo sobre o "patrimônio". São autores de discursos monopolizantes, pois criam os critérios e as condições do exercício da voz autorizada em nome da "causa" e de usos monopolizados, já que são pessoalmente vinculados à problemática e constituem-se em mediado- 
res dotados de função crítica e de exclusividade (Silverman, 1977).

No segundo caso, observa-se que ideias como as de "herança", "transmissão", "geração", "memória", são reiteradamente acionadas no repertório das justificações da palavra autorizada dos especialistas da "cultura popular" no Maranhão. Essas categorias conformam as bases de fundamentação e atualização da "tradição" (abonando a invenção e o reconhecimento de uma ancestralidade) que permitem respaldar o "presente" e justificar determinada fase de uma cultura específica, bem como da imprescindibilidade do trabalho de mediação (entre domínios, linguagens, períodos, etc.) operado por agentes "habilitados" (garantindo a posição de intérpretes e porta-vozes da "tradição" e da "cultura"). Segue-se a ideia de que "a utilidade em particular de uma tradição é de oferecer a todos aqueles que a enunciam e a reproduzem no dia-a-dia o meio de afirmar sua diferença e, por isso mesmo, de assentar sua autoridade" (Lenclud, 1987: 119). Disso decorre a importância de se refletir sobre as bases das interpretações oferecidas e as bases sociais dos intérpretes, revelando os princípios subjacentes ao "unanimismo social" que, muitas vezes, impregna a própria lógica de exercício das ciências sociais ${ }^{21}$.

Em ambos, observa-se a articulação entre três níveis analíticos $\left.{ }^{22}: 1\right)$ o estabelecimento de uma "referência objetiva" a um "passado substancializado" que fundamenta o "patrimônio" como herança disputada por seus próprios arquitetos/guardiões; 2) a fixação de uma "referência subjetiva" a um "passado compartilhado", ao qual, mediante os enquadramentos da memória, são atribuídos elementos (heróis, eventos, experiências, etc.) que unificam os agentes em um espólio comum; 3) a objetivação de uma "referência formalizada" que certifica a continuidade (justificada) do passado no presente por meio da conformação de símbolos, ritos, repertórios, entre outros, que garantem sua existência.

As representações sobre o que constitui a singularidade da "cultura" no e do Maranhão estão intimamente relacionadas aos usos sociais que os agentes podem mobilizar nas suas inserções sociais e lutas políticas. No entanto, a possibilidade de fixar uma posição de liderança na batalha entre porta-vozes e gestores da cultura passa pelo reconhecimento de um conjunto de símbolos, imagens e versões sobre os desdobramentos históricos e as características do "povo maranhense" e do "Maranhão".

Independentemente das posições e posicionamentos dos agentes, até então se observou a preponderância de um referencial dominante multidimensional, que acaba pautando as versões alternativas e, assim, se reproduzindo nas percepções ambíguas que estruturam os discursos e práticas. Tal como apontou Coradini (1994) para as políticas sociais, há estratégias de "importação" e "adaptação" de referenciais, antes que um "processo de 'invenção' de 'problemas' e
21. A “(...) multiplicidade de tradições no seio de uma sociedade [é] fenômeno que tende às vezes a ser ocultado por uma etnografia demasiadamente impregnada de unanimismo social e que o estudo das sociedades mais estratificadas coloca em evidência. Cada grupo, cada entidade social busca sua tradição indo colocar no passado o pavilhão que the convém". (Lenclud, 1987: 119).

22. Proposta por Haegel (1990) e aplicada por Grill (2008) para a análise do universo político. 
respectivas 'soluções' que vão surgindo conforme o estado das relações de força na dominação social e política". Disso resulta “(...) uma espécie de superposição de referenciais, contraditórios entre si, com chances desiguais de institucionalização e de implementação efetiva" (ibidem: 492).

Não estão em questão o "passado" de "opulência" e o período de "decadência" que deslocou o estado de um caminho tido como quase "natural" de destaque nacional que tivera outrora (certificado no panteão das suas personalidades) para o esforço contínuo de reconquista e reafirmação de uma posição central, sobretudo, da dimensão cultural. A "herança europeia" objetivada na arquitetura, na música, no teatro, no gosto pela literatura, etc. se constitui num trunfo indispensável e inconteste. A "herança dos negros e índios" permite compor o quadro da "diversidade", da valorização da "tradição" e do "popular", manifestados nas festas e religiosidade, mas igualmente apropriados na produção de bens culturais pelos "não populares".

Questiona-se o seu uso, questionando o monopólio da imposição de sentidos, dos seus usos legítimos e, principalmente, de quem está apto para fazê-lo. Nesses movimentos e posicionamentos, emerge um lugar qualificado para os mediadores: aquele de produzir e disputar o que deve ser "exumado", "redescoberto", "reabilitado", por meio de recomposições, colagens e retraduções próprias à "produção da autenticidade" (Fabiani, 2003: 367-368).

Abstract: The article analyses as a group of practices, resources and representations activated by spokespeople for "culture" in Maranhão. Through the analysis of the repertoires of mobilization, the insertion spaces and the profiles of social agents that dispute legitimate authority to define what "culture" is in the state, the intention is to reveal some social conditioning incident in the exercise of cultural mediation and in the work of production of public policy.

Keywords: mediation; culture; public policy; popular culture; heritage

\section{Referências}

AlmeidA, A. W. B. (2008) A ideologia da decadência: leitura antropológica a uma história da agricultura do Maranhão. Rio de Janeiro: Editora Casa 8/ Fundação Universidade do Amazonas.

AndRĖs, L. P. C. C. (2006) "Arquitetura”. In Perfil Cultural e Artístico do Maranhão, http://www.perfilcultural.com.br/.

Anjos, J. C. (2002) Intelectuais, literatura e poder em Cabo Verde: lutas de definição da identidade nacional. Porto Alegre (Brasil): UFRGS/IFCH; Praia (Cabo Verde): INIPC. 
ARRETChe, M. (2003) "Dossiê agenda de pesquisa em políticas públicas (Apresentação)". RBCS, Vol. 18, n. 51, fevereiro de 2003.

Borralho, T. (2006) "Artes cênicas". In Perfil Cultural e Artístico do Maranhão. http://www.perfilcultural.com.br/.

Bourdieu, P. (1998) “O capital social”. In Nogueira, M. A.; Catani, A. Pierre Bourdieu. Escritos de educação. Petrópolis, RJ: Vozes.

- (1996) "A linguagem autorizada: as condições sociais da eficácia do discurso ritual". In BOURDIEU, Pierre. A economia das trocas lingüísticas. São Paulo: EDUSP: 85-96.

CARDoso, L. C. M. (2008) O teatro do poder: cultura e política no Maranhão. Dissertação de Mestrado, PPGCS/Universidade Federal do Maranhão.

Carvalho, M. M. P. (2006) "Cultura Popular". In Perfil Cultural e Artístico do Maranhão. http://www.perfilcultural.com.br/

CavalCanti, M. L. V. C. (2009) "Por uma antropologia dos estudos de folclore. $O$ caso do Maranhão". In Ferretti, S. \& Ramalho, J. R. (orgs.), Amazônia. Desenvolvimento, meio ambiente e diversidade sociocultural. São Luís: EDUFMA: 199-220.

Collovald, A. \& Gaiti, B. (1991) “Des causes qui 'parlent'...”. Politix, n 16: 7-22.

CoRAdinI, O. L. (1998a) "Origens sociais, mediação e processo eleitoral em um município de imigração italiana”. In Barreira, I. \& Palmeira, M. (orgs.), Candidatos e candidaturas: enredos de campanha eleitoral no Brasil. São Paulo: Annablume: 91-117.

. (1998b) Elites Culturais e Concepções de Política no Rio Grande do Sul entre as décadas de vinte e sessenta. Relatório de Pesquisa para CNPq. Porto Alegre.

. (1994) "Crise' conjuntural das políticas 'sociais' ou de referenciais?". Ensaios FEE. Porto Alegre, ano 15, $\mathrm{n}^{\circ}$ 2,: 489-501.

FABIANI, J.-L. (2003) "A Córsega ou as servidões da autenticidade". Revista Sociologias. Porto Alegre, ano $5, n^{\circ} 9$, jan/jun.

Ferretti, S. (2006) "Depoimento. Memória de Velhos". In Depoimentos. Memória oral da culta popular maranhense. Vol. VI. CMF/SECMA: 95-168. 
GRILL, I. G. (2008) "Heranças políticas" no Rio Grande do Sul. São Luís: EDUFMA.

HaEgel, F. (1990) "Memoire, Héritage, Filiation. Dire le gaullisme et se dire gaulliste au RPR". Revue Française de Science Politique, Vol. 40, n. 6: 864-879.

JoBERT, B. (1995) "Rethorique politique, controverses scientifiques et construction des normes institutionnelles: esquisse d'un parcours de recherché". In Faure, A.; Pollet, G. \& Warin, P. (orgs.), La construction du sens dans les politiques publiques: débats autour de la notion de referential. Paris: Editions L'Harmattan: 13-24.

LANDÉ, C. H. (1977) "Introduction: the dyadic basis of clientelism". In Schmidt, S. W. et alli. (eds.) Friends, Followers and Factions. A Reader in political clientelism. Berkeley, University of California Press.

LencLud, G. (1987) “La tradition n'est plus ce qu'elle était”. Terrain 9, octobre: 110-123.

LeNoIR, R. (1998) “Objeto sociológico e problema social”. In Champagne, Patrick et al. Iniciação à prática sociológica. Rio de Janeiro: Vozes: 59-06.

Moraes, J. (2006) “Literatura”. In Perfil Cultural e Artístico do Maranhão. http:// www.perfilcultural.com.br/

MulleR, P. (1995) "Les politiques publiques comme construction d'un rapport au monde". In Faure, A.; Pollet, G. \& Warin, P. (orgs.), La construction du sens dans les politiques publiques: débats autour de la notion de referential. Paris: Editions L'Harmattan: 153-179.

Prochasson, C. (1993) Les intellectuels, le socialisme et la guerre. Paris: Seuil.

REIS, E. T. (2008a) “Em nome da 'participação popular': constituição de uma 'causa legítima' e disputas por sua definição no Rio Grande do Sul”. Revista Pós Ciências Sociais, Vol. 5, n. 9/10, jan/dez: 105-132.

. (2008b) “A 'arte' da intervenção política: carreiras e destinos de protagonistas que 'lutaram contra a ditadura' no Rio Grande do Sul". In Coradini, O. L. (org.), Estudos de grupos dirigentes no Rio Grande do Sul: algumas contribuições recentes. Porto Alegre, Editora da UFRGS: 43-60.

REIS, E. T. \& GRILL, I. G. (2008) “Letrados e Votados: lógicas cruzadas do engajamento político no Brasil”. Revista Tomo, n. 13, jul/dez: 127-168. 
SAWICKI, F. (1997) Les Reseaux du Parti Socialiste. Paris: Belin.

- (1999) "Classer les hommes politiques. Les usages des indicateurs de position sociale pour la compréhension de la professionnalisation politique". In Offerlé, M. La profession politique XIX-XX siècles. Paris: Éditions Belin.

SEIDL, E. (2007) "Intérpretes da história e da cultura: carreiras religiosas e mediação cultural no Rio Grande do Sul". Anos 90 . Porto Alegre, Vol. 14, n. 26, dez: 77-110.

SILVA, J. R. C. (2009) A construção do patrimônio: a trajetória de preservação do Centro Histórico de São Luís. Dissertação de Mestrado, PPGCS/Universidade Federal do Maranhão.

Silverman, S. (1977) "Patronage and Community-nation relationships in central Italy". In Schmidt, S. W. et al. (eds.) Friends, Followers and Factions. A Reader in political clientelism. Berkeley, University of California Press: 293-304.

Sobrinho, J. (2006) “Música”. In Perfil Cultural e Artístico do Maranhão http:// www.perfilcultural.com.br/.

TEIXEIRA, A. et alii. (2008). Memória de Velhos. Depoimentos. Memória oral da culta popular maranhense. São Luís: CMF/SECMA, Vol. VII.

ThoenIG, J.-C. (1985) "L’analyse des politiques publiques". In Grawitz, M. \& Leca, J. Les poliques publiques. Paris: Presses Universitaires de France. . (2007) "Recuperando a ênfase na dimensão pública dos estudos organizacionais". Revista de Administração Pública, Vol. 41: 9-36. 